\title{
Iridium-mediated Bond Activation and Water Oxidation as an Exemplary Case of CARISMA, A European Network for the Development of Catalytic Routines for Small Molecule Activation
}

\author{
Giulia Licinia and Martin Albrecht ${ }^{\star b}$
}

\begin{abstract}
CARISMA is a currently running COST Action that pools leading European experts in computational and experimental chemistry to foster synergies for developing new catalytic processes for the transformation of abundant small molecules such as water, carbon dioxide, or ammonia into high-value chemicals and energyrelevant products. CARISMA promotes new collaborations, exchange of knowledge and skills, frontier training to young as well as established researchers, and a platform for the advancement of theoretical and experimental research in an iterative process, comprised of expertise in various connate domains including synthesis, catalysis, spectroscopy, kinetics, and computational chemistry. These interactions stimulate the discovery of new and efficient catalytic processes, illustrated in the second part of this contribution with the collaborative development of powerful iridium-based complexes for bond activation and water oxidation catalysis.
\end{abstract}

Keywords: CARISMA · COST action · Homogeneous catalysis

\section{Introduction}

The availability of efficient catalytic technologies is crucial for a modern society and prospering economy. It has been estimated that the production of about $80 \%$ of all chemicals involves at least one catalytic reaction step, often more, and that the total value of goods produced through catalysis is around $€ 400$ billion per annum. ${ }^{[1]}$ Industrial processes involve predominantly heterogeneous catalysis, though the development of homogeneous catalysts has significant application potential, in particular since homogeneous catalytic systems are well-defined on a molecular scale and their activity and/or selectivity can often be custom-tailored by rational methods. Indeed, a high level of mechanistic insights has been obtained for selected homogeneous catalysts, thus providing access to rationally match substrates and catalysts for

\footnotetext{
${ }^{*}$ Correspondence: Prof. Dr. M. Albrecht ${ }^{\mathrm{a}}$ Tel.: +41316314221

E-mail: martin.albrecht@dcb.unibe.ch

aDipartimento di Scienze Chimiche

Universita degli Studi di Padova

Via Marzolo 1

35131 Padova, Italy

bepartment of Chemistry \& Biochemistry

University of Bern

Freiestrasse 3

$\mathrm{CH}-3012$ Bern, Switzerland
}

optimal performance. [2] Generally, however, the development and optimization of catalysts remains empirical and therefore requires significant resources in terms of time, money, and manpower.

As we gradually face a shortage of fossil feedstocks, the importance of sustainable transformations increases and requires an efficient exploitation of abundant and renewable resources both for application in synthesis and energy production and storage. To address these challenges in a comprehensive and cooperative manner, a COST Action has been launched with the acronym CARISMA (CAtalaytic RoutInes for Small Molecule Activation; CM1205), ${ }^{[3]}$ with the authors as Chair and Vice-chair, respectively. We are delighted that this special issue of CHIMIA features the same theme and a strong contribution from members of the Action as guest editors and authors. ${ }^{4]}$

The aim of CARISMA is "to attain a fundamental understanding of the catalytic principles involved in the transition metalcatalyzed activation of small molecules through concerted research activities in silico and in vitro, using an integral approach to catalysis that includes synthetic, mechanistic, and computational techniques" (Fig. 1). ${ }^{[3]}$ The parallel theoreti$\mathrm{cal} /$ experimental approach is based on using most modern trends in computational chemistry to reliably mimic and rationalize the activity and selectivity of powerful catalysts. CARISMA specifically aims at applying this integral approach to design and improve catalytic systems for the efficient conversion of small and generally unreactive molecules including $\mathrm{CO}_{2}, \mathrm{CO}$, $\mathrm{O}_{2}, \mathrm{H}_{2} \mathrm{O}, \mathrm{N}_{2}$, or $\mathrm{NH}_{3}$ to produce useful intermediates. This focus has an obvious long-term impact on synthetic domains (disclosing new synthons for the preparation of value-added intermediates and pharmaceutical ingredients), environment (depletion of atmospheric $\mathrm{CO}_{2}$ ), and on harnessing energy in a sustainable manner (biomass conversion, storage of transient renewable energy such as solar, wave, or wind into chemical bonds, e.g. through artificial photosynthesis). [5]

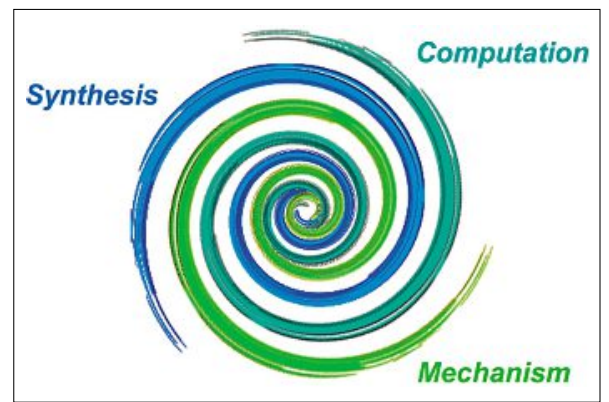

Fig. 1. Logo of COST Action CM1205 (see ref. [3]) representing the interdigitated activities within CARISMA to develop routines for small molecule activation involving strong interactions between synthetic, mechanistic, and computational experts. 


\section{The CARISMA Network}

The network has brought together more than 60 experts with diverse backgrounds, many of whom have achieved significant breakthroughs in metal-mediated homogeneous bond activation. For example, CARISMA members have contributed significantly to the development of state-ofthe-art catalysts for the activation of small molecules, ${ }^{6]}$ including water oxidation catalysts based on iron, ruthenium or iridium, ${ }^{[7]}$ ruthenium complexes for functionalizing $\mathrm{NH}_{3}$ and $\mathrm{N}_{2},{ }^{[8]}$ and first row transition metals for the conversion and reduction of $\mathrm{CO}_{2} \cdot{ }^{\left[{ }^{[9}\right.} \mathrm{A}$ considerable set of catalytic systems has been developed for $\mathrm{O}_{2}$ activation, which includes catalysts based on both early and late transition metals. ${ }^{[6]}$ Hence, transition metal catalysis has unveiled a broad range of synthetic strategies to consider exploitation of typically unreactive small molecules.

CARISMA is therefore directing a strong scientific focus towards three types of small molecules:[3] oxygen-containing small-molecule conversion (reduction and splitting of $\mathrm{O}_{2}$, oxidation of $\mathrm{H}_{2} \mathrm{O}$ ), activation of nitrogen-based small molecules (reduction of $\mathrm{N}_{2}$, oxidation of $\mathrm{NH}_{3}$ ), and carbon-centered small molecules, specifically the fixation and reduction of $\mathrm{CO}_{2}$ and $\mathrm{CO}$ (Fig. 2). The activation of these small molecules is at the forefront of modern catalysis and has a significant impact on synthesis and beyond. Moreover, the activation of small molecules is ideally suited to achieve substantial progress in catalysis in silico, since the complexity of the target substrate is reduced to a minimum. Therefore, a major focus is directed towards developing a sophisticated model, an in-depth understanding, and eventually an approach to predict the reactivity of the metal center and the effects imparted by the ligands. An integrated approach of all activities is pertinent to the success of these efforts and involves the utilization of most modern methodologies of synthesis, mechanistic investigations, and computational tools. Apart from the vast application potential arising from efficient processes for the activation of small molecules, this network endeavor also constitutes an exciting academic challenge due to the very strong bonds featured in small molecules such as $\mathrm{N}_{2}, \mathrm{CO}, \mathrm{O}_{2}$. Catalytic and stoichiometric methodologies for the activation and cleavage of such bonds hence reveal also a great importance from a fundamental and mechanistic viewpoint.

The network pools globally leading expertise in synthesis, mechanistic understanding, and computational modeling of reactions in an effort to facilitate mechanistically informed processes to accelerate the development of efficient catalytic

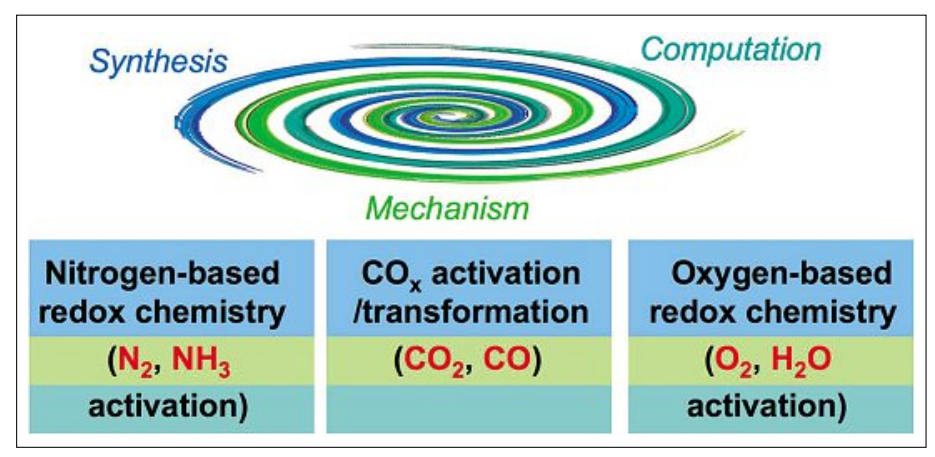

Fig. 2. The three main activity themes of CARISMA, all involving an integrated approach based on synthetic, mechanistic, and computational expertise.

systems. Such an approach is particularly attractive since theoretical methods have attained high accuracy at a rate that enables the calculation of entire reaction mechanisms and to verify/falsify transition state energies and the stability of intermediates by using sophisticated experimental procedures. Due to their high reliability, calculations constitute a most valuable tool for understanding and improving homogeneous catalysts, especially with small molecule substrates and a catalytically active metal center that is located in a well-defined environment.

\section{A Case Study: Iridium-based Bond Activation and Molecular Water Oxidation Catalysis}

Work in the laboratories of one of us has recently focused on the use of triazolylidenes as powerful mesoionic ligands to transition metals. ${ }^{[10]}$ These ligands, readily available through versatile click chemistry and subsequent $\mathrm{N}$-alkylation, ${ }^{[11]}$ contribute to the arsenal of N-heterocyclic carbene-type ligands. ${ }^{[12]}$ They reveal peculiar properties due to their mesoionic properties, ${ }^{[13]}$ formally featuring a resonanceconjugated positive and negative charge in the heterocycle. When coordinated to a late transition metal center, these ligands impart interesting and often catalytically relevant behavior.[14] Specifically, triazolylidene iridium(III) complexes have been demonstrated to be highly active for $\mathrm{C}-\mathrm{H}$ and $\mathrm{C}-\mathrm{N}$ bond activation. For example, the triazolylidene complex 1 with a pending pyridinium substituent undergoes either $\mathrm{C}-\mathrm{H}$ or $\mathrm{C}-\mathrm{N}$ bond activation, and the reaction trajectory is highly dependent on the presence or absence of acetate ions and the applied reaction conditions. Thus, thermal treatment of the monodentate triazolylidene complex $\mathbf{1}$ provides a mixture of complexes $\mathbf{2}$ and $\mathbf{3}$ resulting either from $\mathrm{C}\left(\mathrm{sp}^{2}\right)-\mathrm{H}$ or from $\mathrm{C}\left(\mathrm{sp}^{3}\right)-\mathrm{H}$ bond activation, respectively (Scheme 1). ${ }^{[15]}$ The process is strongly influenced by the substituent at the triazolylidene ligand and $\mathrm{C}\left(\mathrm{sp}^{3}\right)-\mathrm{H}$ bond activation is completely suppressed when this substituent is an alkyl group.
Computational analysis of this process in a CARISMA collaboration involving Eric Clot has revealed that the two bond activation processes are not competitive and that $\mathrm{C}\left(\mathrm{sp}^{2}\right)-\mathrm{H}$ bond activation is favored by $7-16 \mathrm{~kJ} \mathrm{~mol}^{-1}$ irrespective of the substituents $\mathrm{R}$, thus suggesting the exclusive formation of complexes 2. ${ }^{[16]}$ However, computation has further predicted that for $\mathrm{R}=$ benzyl, the $\mathrm{C}\left(\mathrm{sp}^{2}\right)-\mathrm{H}$ bond activation of the benzyl group is preferred over the activation of the same type of bond in the pyridinium substituent, thus leading to complex 4 (Scheme 2). Moreover, a lowbarrier pathway has been calculated for an intramolecular transcyclometalation, [17] which involves the selective proton transfer from the $\mathrm{N}-\mathrm{CH}_{3}$ group to the metallated benzyl unit and thus transforms intermediate 4 to complex 3 . This transcyclometalation exclusively involves the methyl group in the pyridinium ring, and thus constitutes a selective process for the formation of complex 3. Unlike our first assumption, computation predicts an indirect activation of this $\mathrm{C}\left(\mathrm{sp}^{3}\right)-\mathrm{H}$ bond involving the cyclometalated complex 4 as critical intermediate. Experimentally, this reaction trajectory has been validated by the reaction of 1 at room temperature, which allowed for the spectroscopic characterization of a mixture of $\mathbf{2}$ and $\mathbf{4}$. In addition, separation of $\mathbf{4}$ has demonstrated that this complex selectively and spontaneously transforms to the ylide complex 3 resulting from formal $\mathrm{C}\left(\mathrm{sp}^{3}\right)-\mathrm{H}$ bond activation. Calculations and experimental data are in excellent agreement with respect to the product ratios of $\mathbf{2} v s \mathbf{3}$ (and $\mathbf{4}$ as a selective precursor of 3 ) and also converge with regards to the activation barrier for the transcyclometalation process $\left(\Delta \mathrm{G}^{\ddagger}=110 \pm 7 \mathrm{~kJ} \mathrm{~mol}^{-1}\right.$ from kinetic experiments, $114.6 \mathrm{~kJ} \mathrm{~mol}^{-1}$ from theory), thus validating the interdigitated theory/experimental approach. Moreover, the reaction model is supported by the fact that cyclometalaton of phenyl substituents produces a stable complex that does not undergo further transcyclometalation, thus representing a model for the cyclometalated intermediate $\mathbf{4}$, albeit with different steric constraints. 


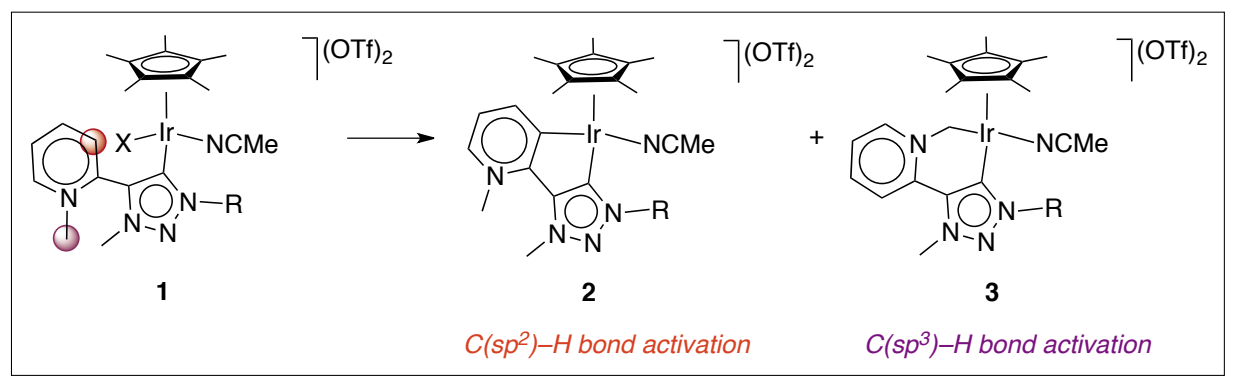

Scheme 1. The selectivity of iridium-mediated $\mathrm{C}-\mathrm{H}$ bond activation of a pending pyridinium substituent is directed by a remote substituent $\mathrm{R}$, favoring products either from $\mathrm{C}\left(\mathrm{sp}^{2}\right)-\mathrm{H}$ (for $\mathrm{R}=$ alkyl) or from $\mathrm{C}\left(\mathrm{sp}^{3}\right)-\mathrm{H}$ bond activation $(\mathrm{R}=$ benzyl).

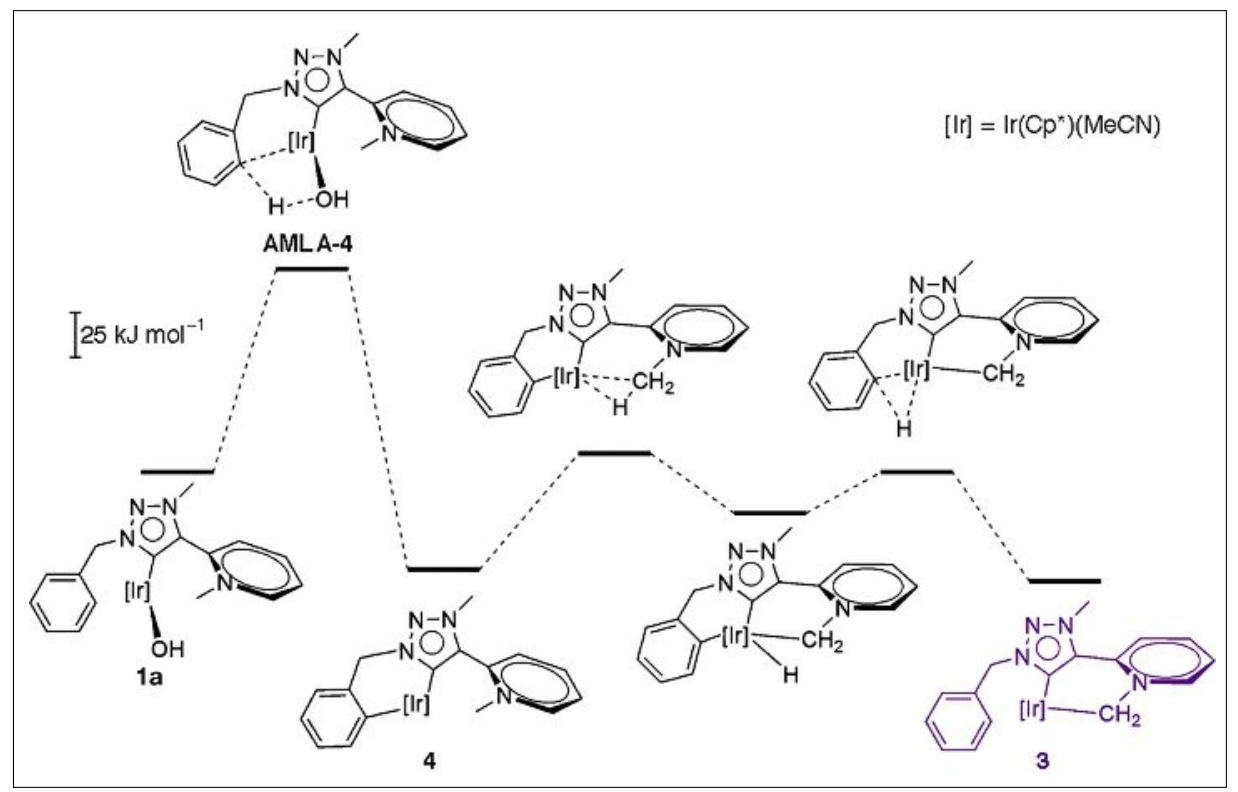

Scheme 2. Computationally predicted and experimentally validated reaction trajectory leading to $\mathrm{C}\left(\mathrm{sp}^{3}\right)-\mathrm{H}$ bond activation via a cyclometallated intermediate $\mathbf{4}$ and subsequent transcyclometallation through an iridium(v) species.

Attempts to accelerate the transcyclometalation process by adding $\mathrm{OAc}^{-}$ions as potential proton shuttles ${ }^{[18]}$ leads to a different outcome and complex 4 undergoes selective $\mathrm{N}-\mathrm{C}$ rather than $\mathrm{C}-\mathrm{H}$ bond activation, thus providing complex 6 (Scheme 3). ${ }^{[19]}$ Complex 6 is the product of a selective methylene transfer from $\mathrm{N}_{\mathrm{p}}$ to the iridium-bound carbon of the benzyl substituent, followed by solvent activation. Isotope labeling of the methyl groups has demonstrated that the process is selective, and modification of the solvent (e.g. benzonitrile instead of $\mathrm{MeCN}$ ) leads to the introduction of a terminal phenyl group in the new complex $\mathbf{6 b}$. The reaction does not need to start from the cyclometalated intermediate, and indeed proceeds from the triazolium ligand precursor $\mathbf{5}$, thus providing a pathway for the intramolecular alkylation of a benzylic group with a rather unreactive alkylating agent, viz. a methylpyridinium group. From a functional point of view, this process is highly reminiscent of methyl transferase activity. For example, S-adenosyl methionine (SAM) selectively methylates $\mathrm{sp}^{2}$-hybridized carbons of DNA realized with a number of low-cost Earthabundant metal catalysts. ${ }^{[21]}$ Water oxidametallated benzyl unit at a triazolylidene iridium scaffold. tion however is more complex, energetically much more demanding $\left(E^{\circ}=1.23 \mathrm{~V}\right)$, and requires a highly robust catalyst because of the harshly oxidizing conditions. Following pioneering work by Bernhard on iridium(III) complexes, ${ }^{[22]}$ and Crabtree's subsequent expansion to $\mathrm{Cp}^{*}$-containing iridium(III) complexes, ${ }^{[23]}$ a plethora of derivatives have been discovered to catalyze water oxidation, ${ }^{[24]}$ generally in the presence of a sacrificial oxidant. ${ }^{[25]}$ Mechanistic investigations have been exacerbated by the complexity of the reaction and by the fact that colloidal $\mathrm{IrO}_{\mathrm{x}}$ is also catalytically active. Recent work using a variety of sophisticated techniques, including in situ analysis by EXAFS and quartz microbalance, ${ }^{[26]}$ as well as kinetic analyses indicate that a number of complexes indeed rapidly heterogenize to form a catalytically active phase that does not include key ligands, while other complexes remain homogeneous and form a molecularly defined compound as catalytically most competent species, at least when turnover frequencies are high.

Extensive kinetic investigations on complexes 2 and a related analogue 7 containing a pyridine rather than a pyridylidene as chelating group have revealed that these complexes are highly active (TONs in excess of 38,000) and that their oxygen evolution kinetics follow a very welldefined and recurring rate law (Fig. 3).[27] These analyses as well as further indications, such as the excellent stability of the complexes in the full $\mathrm{pH}$ range, ${ }^{[28]}$ support a molecularly operating complex rather than a heterogenized phase. Extensive electrochemical analysis of complex 7 in a CARISMA collaboration involving Antoni Llobet indicate regimes where proton-coupled electron transfer (PCET) processes are available. ${ }^{[29]}$ These investigations also flag potential issues that may arise from utilizing co-solvents, since MeCN coordination to the iridium center in $\mathbf{7}$ is much stronger than $\mathrm{OH}_{2}$ coordination (Scheme 4). Hence, $\mathrm{MeCN}$ as a co-solvent has a negative impact on accessing the catalytically relevant aquo complex.

Since the mechanistic investigations support a molecularly defined species as catalytically most competent unit, ligand modification constitutes an attractive

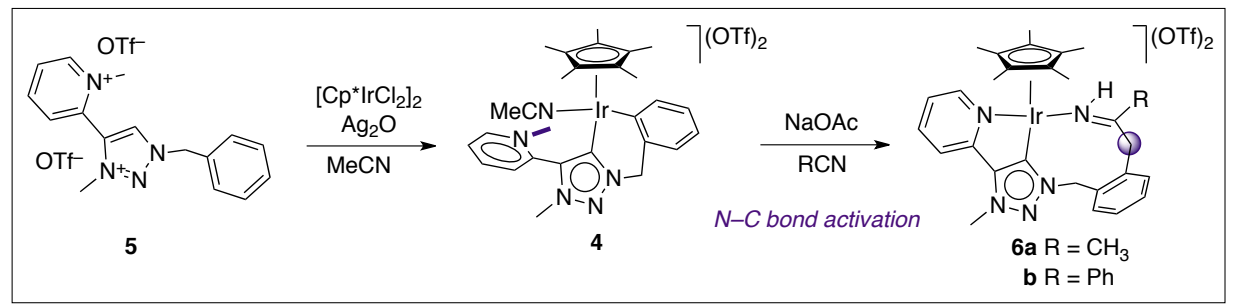

Scheme 3. Acetate-promoted C-N bond activation and methylene transfer from pyridinium to a 


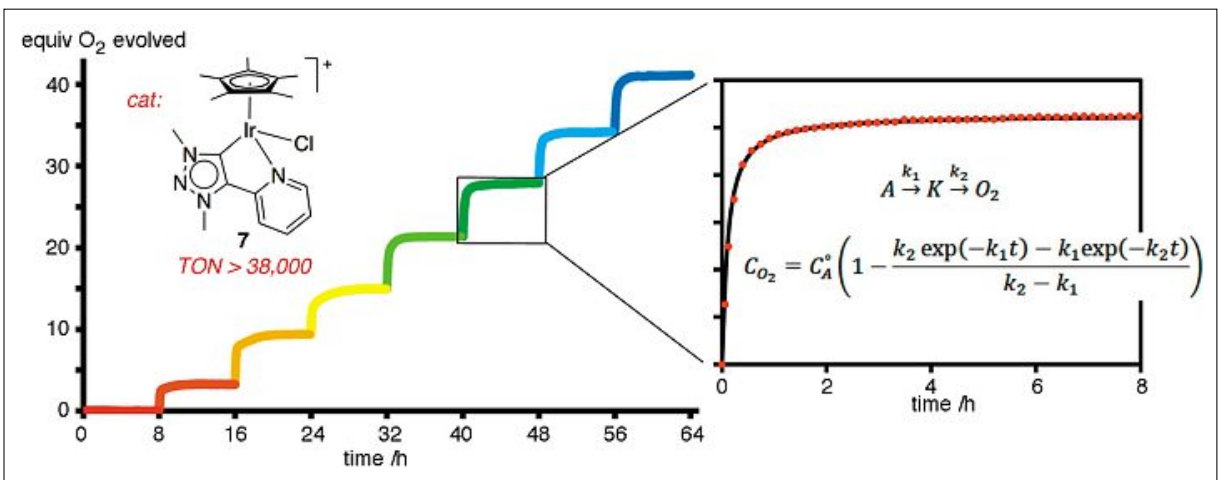

Fig 3. Oxygen evolution traces for complex 7 upon sequential additions of 20 equivalents cerium(Iv) every $8 \mathrm{~h}$, indicating a requirement of some 30 equivalent cerium(IV) for catalyst activation and subsequent quantitative oxygen formation; the inset shows the excellent fit of the measured data points (red) with the rate of oxygen evolution in a consecutive reaction that involves the activation of water $(\mathrm{A})$ and the formation of a kinetically competent intermediate $(\mathrm{K})$ prior to $\mathrm{O}_{2}$ evolution.

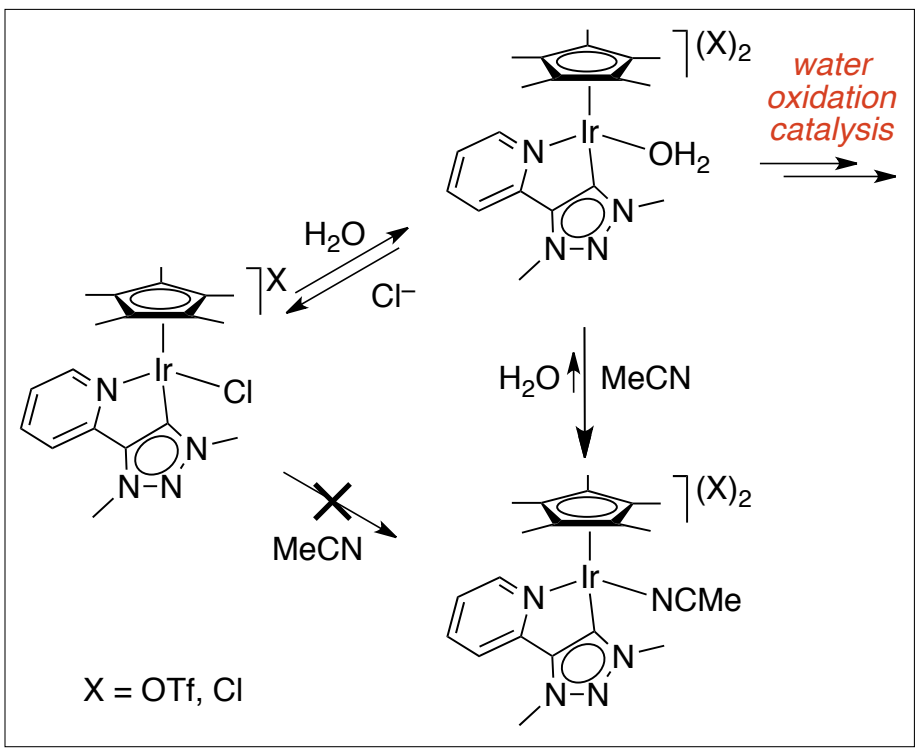

tail may induce aggregation, and extensive DOSY NMR analyses indicate the formation of small entities involving 2-4 iridium centers at best. Potentially, di-, tri-, or tetrameric species may form a hydrophobic patch which facilitates the formation of an iridium(v) oxo intermediate to further induce $\mathrm{O}-\mathrm{O}$ bond formation. Alternatively, the formation of small aggregates may induce facile disproportionation of two high-valent $\mathrm{Ir}=\mathrm{O}$ species to produce $\mathrm{O}_{2}$ and low-valent iridium centers via the so-called I2M process (interaction of two metal centers). ${ }^{[32]}$ The introduction of hydrophobic alkyl chains may become an attractive concept for boosting the catalytic activity of other water oxidation catalysts.

\section{Conclusions and Outlook}

Scheme 4. Relevant equilibria of complex 7 in water and in the presence of $\mathrm{MeCN}$, indicating a prohibitive effect of $\mathrm{MeCN}$ to initiate water oxidation catalysis; redox potentials of the different species vary significantly.
CARISMA is a highly successful network that has delivered many new insights over the last few years and will surely continue to do so in the remaining year and a bit that it is still operational. One of the key strengths is probably the large diversity of activities in the area of small molecule activation that includes $\mathrm{CO}_{2}$ activation, $\mathrm{NH}_{3}$ and $\mathrm{N}_{2}$ activation, $\mathrm{H}_{2} \mathrm{O}$ oxidation towards water splitting, as well as the synthetic utilization of $\mathrm{O}_{2}$.

The work illustrated here on understanding and facilitating iridium-mediated activation of strong $\mathrm{C}-\mathrm{H}$ and $\mathrm{C}-\mathrm{N}$ bonds as well as on iridium-based molecular water oxidation catalysis demonstrates that a strong interdigitation of computational, mechanistic, and synthetic expertise provides an attractive base for spurring cata- methodology for catalyst optimization. In a CARISMA collaboration with Alceo Macchioni, we have pursued this avenue by incorporating longer alkyl chains into the ligand framework. ${ }^{[30]}$ Thus replacing the methyl group in complex $\mathbf{8}$ by an octyl group as in complex 9 has been probed, initially to investigate whether this alkyl group is susceptible to oxidative cleavage (Fig. 4). No such reactivity has been observed for complex 9. Instead, the activity of water oxidation is raised by a full order of magnitude, revealing the highest turnover frequencies (TOFs) reported for iridium thus far. While most $\mathrm{Cp}^{*}$ iridium(III) complexes display maximum TOFs around $0.2-0.5 \mathrm{~s}^{-1}$ (e.g. $0.16 \mathrm{~s}^{-1}$ for complex 8), complex 9 catalyzes water oxidation at rates as high as $1.6 \mathrm{~s}^{-1}$. This substantial rate-enhancement upon inclusion of a hydrophobic substituent in the ligand framework seems counterintuitive at first. Spectroscopic and MS analyses tend to suggest a rapid (partial) oxidation of the $\mathrm{Cp}^{*}$ unit. ${ }^{[31]}$ In addition, the long alkyl

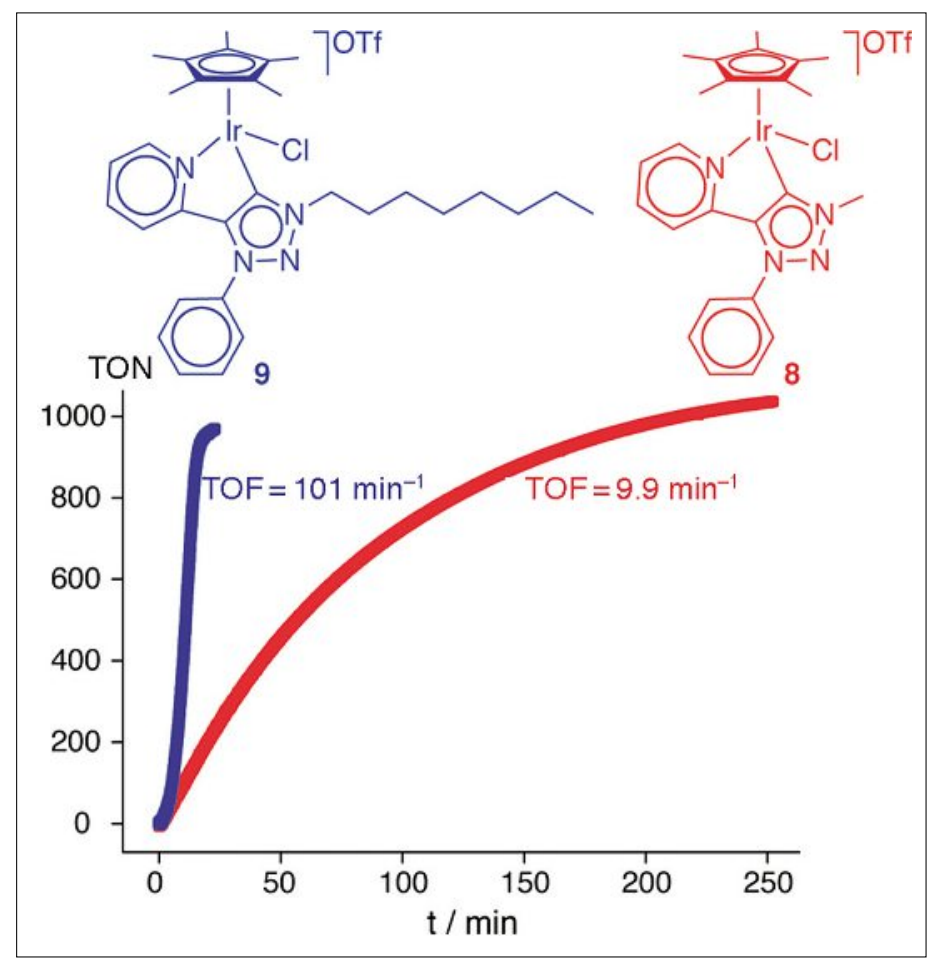

Fig. 4. Substantial rate enhancement of iridium water oxidation catalysis upon introduction of a lipophilic octyl group on the triazolylidene ligand. 
lyst discovery and for improving and optimizing catalytic performance.

\section{Acknowledgements}

Our research in this area has been supported by the Swiss National Science Foundation, the European Research Council, the Irish Research Council, and Science Foundation Ireland, and of course by COST Action CM1205, Catalytic Routines for Small Molecule Activation (CARISMA).

Received: April 24, 2015

[1] 'Applied Homogeneous Catalysis', Eds. A. Behr, P. Neubert, Wiley-VCH: Weinheim, 2012.

[2] For an example, see: S. T. Henriksen, P.-O. Norrby, P. Kaukoranta, P. G. Andersson, J. Am. Chem. Soc. 2008, 130, 10414.

[3] For further details, see http://www.cost.eu/ COST_Actions/cmst/Actions/CM1205 and http://carisma-cost.weebly.com/

[4] a) I. Mellone, F. Bertini, L. Gonsalvi, A. Guerriero, M. Peruzzini, Chimia 2015, 69, 331; b) Á. Kathó, I. Szatmári, G. Papp, F. Joó, Chimia 2015, 69, 339.

[5] a) N. D. McDaniel, S. Bernhard, Dalton Trans. 2010, 39, 10021; b) N. S. Lewis, D. G. Nocera, Proc. Natl. Acad. Sci. USA 2006, 103, 15729; c) 'Molecular Water Oxidation', Ed. A. Llobet, Wiley-Interscience: New York, 2014.

[6] For selected examples, see: a) A. Boddien, D. Mellmann, F., Gaertner, R. Jackstell, H. Junge, P. J. Dyson, G. Laurenczy, R. Ludwig, M. Beller, Science, 2011, 333, 1733; b) V. Conte, A. Coletti, B. Floris, G. Licini, C. Zonta, Coord. Chem. Rev. 2011, 255, 2165; c) G. Licini, V. Conte, A. Coletti, M. Mba, C. Zonta, Coord. Chem. Rev. 2011, 255, 2345; d) V. Khlebnikov, A. Meduri, H. Mueller-Bunz, T. Montini, P. Fornasiero, E. Zangrando, B. Milani, M. Albrecht, Organometallics 2012, 31, 976; e) G. Santoni, M. Mba, M. Bonchio, W. A. Nugent, C. Zonta, G. Licini, Chem. Eur. J. 2010, 16, 645.

[7] For selected examples, see: a) A. Sartorel, P. Miro, E. Salvadori, S. Romain, M. Carraro, G. Scorrano, M. Di Valentin, A. Llobet, C. Bo, M. Bonchio, J. Am. Chem. Soc. 2009, 131, 16051; b) D. G. H. Hetterscheid, J. N. H. Reek, Chem. Commun. 2011, 47, 2712; c) L. Duan, F. Bozoglian, S. Mandal, B. Stewart, T. Privalov, A. Llobet, L. Sun, Nat. Chem. 2012, 4, 418; d) A. Bucci, A. Savini, L. Rocchigiani, C. Zuccaccia, S. Rizzato, A. Albinati, A. Llobet, A. Macchioni, Organometallics 2012, 31, 8071; e) Z. Codolà, J. M. S. Cardoso, B. Royo, M. Costas, J. L. Fillol, Chem. Eur. J. 2013, 19, 7203.

[8] For selected examples, see: a) D. Pingen, D. Vogt, Catal. Sci. Technol. 2014, 4, 47; b) E. Khaskin, M. A. Iron, L. J. W. Shimon, J. Zhang, D. Milstein, J. Am. Chem. Soc. 2010, 132, 8542; c) D. Srimani, Y. Ben-David, D. Milstein, Angew. Chem. Int. Ed. 2013, 52, 4012; d) Y. Gloaguen, C. Rebreyend, M. Lutz, P. Kumar, M. Huber, J. I. van der Vlugt, S. Schneider, B. de Bruin, Angew. Chem. Int. Ed. 2014, 53, 6814.
[9] For selected examples, see: a) C. Fersel, A. Boddien, R. Jackstell, R. Jennerjahn, P. J. Dyson, R. Scopelliti, G. Laurenczy, M. Beller, Angew. Chem. Int. Ed. 2010, 49, 9777; b) Q. Liu, L. Wu, R. Jackstell, M. Beller, Nat. Commun. 2015, 6, doi:10.1038/ncomms6933; c) S. Moret, P. J. Dyson, G. Laurenczy, Nature Communications, 2014, 5, DOI: 10.1038/ ncomms5017; d) C. J. Whiteoak, B. Gjoka, E. Martin, M. Martinez Belmonte, E. C. Escudero Adan, C. Zonta, G. Licini, A. W. Klei, Inorg. Chem. 2012, 51, 1063.

[10] a) P. Mathew, A. Neels, M. Albrecht, J. Am. Chem. Soc. 2008, 130, 13534; b) G. GuisadoBarrios, J. Bouffard, B. Donnadieu, G. Bertrand, Angew. Chem. Int. Ed. 2010, 49, 4759.

[11] a) V. V. Rostovtsev, L. G. Green, V. V. Fokin, K. B. Sharpless, Angew. Chem. Int. Ed. 2002, 41, 2596; b) V. D. Bock, H. Hiemstra, J. H. van Maarseveen, Eur. J. Org. Chem. 2006, 51; c) J. E. Moses, A. D. Moorhouse, Chem. Soc. Rev. 2007, 36, 1249; d) J. E. Hein, V. V. Fokin, Chem. Soc. Rev. 2010, 39, 1302.

[12] For selected reviews, see: a) D. Bourissou, O. Guerret, F. P. Gabbai, G. Bertrand, Chem. Rev. 2000, 100, 39; b) W. A. Herrmann, Angew. Chem. Int. Ed. 2002, 41, 1290; c) F. E. Hahn, M. C. Jahnke, Angew. Chem. Int. Ed. 2008, 47 , 3122; d) A. T. Normand, K. J. Cavell, Eur. J. Inorg. Chem. 2008, 2781; e) M. Poyatos, J. A. Mata, E. Peris, Chem. Rev. 2009, 109, 3677; f) S. Diez-Gonzalez, N. Marion, S. P. Nolan, Chem. Rev. 2009, 109, 3612; g) L. Mercs, M. Albrecht, Chem. Soc. Rev. 2010, 39, 1903; h) A. Monney, M. Albrecht, Coord. Chem. Rev. 2013, 257, 2420; i) L. Yang, O. Schuster, H. G. Raubenheimer, M. Albrecht, Chem. Rev. 2009, 109,3445 ; j) M. Melaimi, M. Soleilhavoup, G. Bertrand, Angew. Chem. Int. Ed. 2010, 49, 8810.

[13] a) According to the IUPAC Golden Book, mesoionic compounds are "Dipolar five(possibly six-) membered heterocyclic compounds in which both the negative and the positive charge are delocalized, for which a totally covalent structure cannot be written, and which cannot be represented satisfactorily by any one polar structure. The formal positive charge is associated with the ring atoms, and the formal negative charge is associated with ring atoms or an exocyclic nitrogen or chalcogen atom. Mesoionic compounds are a subclass of betains." 'IUPAC. Compendium of Chemical Terminology', 2 $2^{\text {nd }}$ ed. (the 'Gold Book') compiled by A. D. McNaught, A. Wilkinson, Blackwell Oxford, UK: Scientific Publications; 1997. See also: b) S. Araki, Y. Wanibe, F. Uno, A. Morikawa, K. Yamamoto, K. Chiba, Y. Butsugan, Chem. Ber. 1993, 12, 1149.

[14] a) J. D. Crowley, A.-L. Lee, K. J. Kilpin, Aust. J. Chem. 2011, 64, 1118; b) K. F. Donnelly, A. Petronilho, M. Albrecht, Chem. Commun. 2013, 49,$1145 ;$ c) B. Schulze, U. S. Schubert, Chem. Soc. Rev. 2014, 43, 2522; d) M. Albrecht, $A d v$. Organomet. Chem. 2014, 62, 111.

[15] R. Lalrempuia, N. D. McDaniel, H. MüllerBunz, S. Bernhard, Albrecht, M. Angew. Chem., Int. Ed. 2010, 49, 9765.
[16] K. F. Donnelly, R. Lalrempuia, H. Müller-Bunz, E. Clot, M. Albrecht, Organometallics 2015, 34, 858 .

[17] a) M. Albrecht, M. Dani, P. Spek, A. L. van Koten, G. J. Am. Chem. Soc. 2000, 122, 11822. b) A. D. Ryabov, R. van Eldik, Angew. Chem. Int. Ed. Engl. 1994, 33, 783.

[18] a) D. L. Davies, S. M. A. Donald, S. A. Macgregor, J. Am. Chem. Soc. 2005, 127, 13754; b) D. Balcells, E. Clot, O. Eisenstein, Chem. Rev. 2010, 110, 749.

[19] R. Lalrempuia, H. Müller-Bunz, M. Albrecht, Angew. Chem. Int. Ed. 2011, 50, 9976.

[20] a) W. A. M. Loenen, Biochem. Soc. Trans. 2006, 34, 330; b) Y. Zhang, X. Zhu, A. T. Torelli, M. Lee, B. Dzikovski, R. M. Koralewski, E. Wang, J. Freed, C. Krebs, S. E. Ealick, H. Lin, Nature 2010, 465, 891

[21] a) Z. Han, F. Qiu, R. Eisenberg, P. L. Holland, T. D. Krauss, Science 2012, 338, 1321; b) Z. Han, W. R. McNamara, M. Eum, P. L. Holland, R. Eisenberg, Angew. Chem. Int. Ed. 2012, 51, 1667.

[22] N. D. McDaniel, F. J. Coughlin, L. L. Tinker, S. Bernhard, J. Am. Chem. Soc. 2008, 130, 210.

[23] J. F. Hull, D. Balcells, J. D. Blakemore, C. D. Incarvito, O. Eisenstein, G. W. Brudvig, R. H. Crabtree, J. Am. Chem. Soc. 2009, 131, 8730.

[24] J. A. Woods, S. Bernhard, M. Albrecht, in 'Molecular Water Oxidation', Ed. A. Llobet, Wiley-Interscience: New York, 2014; pp 113.

[25] a) A. R. Parent, R. H. Crabtree, G. W. Brudvig, Chem. Soc. Rev. 2013, 42, 2247; b) D. G. H. Hetterscheid, J. N. H. Reek, Eur. J. Inorg. Chem. 2014, 742 .

[26] a) H. Junge, N. Marquet, A. Kammer, S. Denurra, M. Bauer, S. Wohlrab, F. Gärtner, M.-M. Pohl, A. Spannenberg, S. Gladiali, M. Beller, Chem. Eur. J. 2012, 18, 12749; b) N. D. Schley, J. D. Blakemore, N. K. Subbaiyan, C. D. Incarvito, F. D'Souza, R. H. Crabtree, G. W. Brudvig, J. Am. Chem. Soc. 2011, 133, 10473.

[27] J. A. Woods, R. Lalrempuia, A. Petronilho, N. D. McDaniel, H. Müller-Bunz, M. Albrecht, S. Bernhard, Energy Env. Sci. 2014, 7, 2316.

[28] a) A. Petronilho, M. Rahman, J. A. Woods, H. Al-Sayyed, H. Müller-Bunz, D. M. J. MacElroy, S. Bernhard, M. Albrecht, Dalton Trans. 2012, 41, 13074; b) A. Petronilho, J. A. Woods, S. Bernhard, M. Albrecht, Chem. Eur. J. 2014, 20, 15775

[29] A. Petronilho, A. Llobet, M. Albrecht, Inorg. Chem. 2014, 53, 12896.

[30] I. Corbucci, A. Petronilho, H. Müller-Bunz, L. Roccigiani, M. Albrecht, A. Macchioni, ACS Catal. 2015, 5, 2714.

[31] a) C. Zuccaccia, G. Bellachioma, O. Bortolini, A. Bucci, A. Savini, A. Macchioni, Chem. Eur. J. 2014, 20, 3446; b) A. Savini, A. Bucci, G. Bellachioma, L. Rocchigiani, C. Zuccaccia, A. Llobet, A. Macchioni, Eur. J. Inorg. Chem. 2014, 690; c) U. Hintermair, S. Sheehan, A. Parent, D. Ess, D. Richens, P. Vaccaro, G. W. Brudvig, R. H. Crabtree, J. Am. Chem. Soc. 2013, 135, 10837.

[32] a) S. Romain, L. Vigara, A. Llobet, Acc. Chem. Res. 2009, 42, 1944; b) A. Petronilho, J. A Woods, S. Bernhard, M. Albrecht, Eur. J. Inorg. Chem. 2014, 708. 